Nikolaos Lavidas* and Alexander Bergs

\title{
On historical language contact in English and its types: state of the art and new directions
}

https://doi.org/10.1515/lingvan-2020-0010

Received February 20, 2020; accepted February 27, 2020

\begin{abstract}
This article presents the state of the art of current research on the different types of language contact in early English. The article's main aim is to show what kinds of phenomena have been investigated until now as possible areas of transfer/borrowing from other languages. We examine the main contact scenarios in Old and Middle English, which involve Latin, Celtic, French and Old Norse. We locate unanswered questions and underexamined hypotheses of historical language contact. We argue that the articles of the Special Collection on Language Contact in the History of English open new directions in the way we can investigate the role of early language contact in the development of English. New methodologies of research, the role of bilingualism in language change but also of the written types of contact, and the various domains of change in grammar, lexicon, and pragmatics offer insights into old and new hypotheses on scenarios of language contact.
\end{abstract}

Keywords: language contact; early English; history of English

\section{Aims and broad questions}

This special collection of articles originates primarily from the workshop on "Historical Language Contact in English and Beyond" (April 1, 2017; organized by Alexander Bergs and Nikolaos Lavidas, as a part of the 23rd International Symposium on Theoretical and Applied Linguistics [ISTAL 23]). The idea of the workshop and the special collection was to bring together scholars interested in systematic study of historical language contact. The focus of the collection itself is on contact-induced changes in the history of English, with the purpose of opening new research perspectives, particularly regarding explanations of change that involve the role of bilingualism. The issues addressed in the articles include, among others: case studies of contactinduced changes in English and approaches to historical bilingualism and language contact, social aspects of historical language contact, and similarities to recent developments and ongoing contact-induced changes.

The role of contact in the development of English has been acknowledged in various recent studies. As stated by Hundt and Schreier (2013), English has been "contact-derived from its very beginnings onwards" (see also Trudgill 2016, among others). For instance, multiple possible contact-induced changes in English resulting from contact with Celtic, Latin, Old Norse and French have been at the center of discussion and debate over the past decades. In this respect, various analyses have been proposed regarding the question of substratal (in the case of Anglo-Saxons and Celts or Norman French and Middle English) or adstratal relationships (in the case of Old English and Norse) among the languages spoken in Britain. The substratal position of a language is related to restricted toponymic borrowing; adstratal positions may lead to the mixing of populations, language shift and even grammatical borrowing. Moreover, we should always distinguish between different types of historical - written or oral - language contact: for instance, in the case of Latin, contact developed through a process of foreign language acquisition and was heavily affected by the dominant position of Latin as a means of literary and spiritual communication (Timofeeva 2010).

*Corresponding author: Nikolaos Lavidas, National and Kapodistrian University of Athens, Faculty of English, Department of Language-Linguistics, Athens, Greece, E-mail: nlavidas@enl.uoa.gr

Alexander Bergs: Osnabrück University, Osnabrück, Germany, E-mail: abergs@uni-osnabrueck.de 
Attempts to analyze changes in the history of English as the result of transfer or borrowing from other languages focus on innovations in later English, including, among others: (a) the periphrastic do, the progressive form, the it-cleft construction and the Northern subject rule, with regard to hypotheses related to the contact with Celtic (e.g., Poussa 1990, Ball 1991; Poppe 2003; Klemola 2013); (b) in the case of hypotheses related to the contact with Latin, the absolute construction (ablativus absolutus), the passive infinitive and the nominativus- and accusativus-cum-infinitivo constructions (e.g., Fischer 1991, 1994, 2013; Kohnen 2003; Nagucka 2003; Timofeeva 2010); (c) the historical present tense, the use of second-person pronouns and the pragmatics of politeness, the post-posed adjectives, the wh-relatives and the causative $d o$, with regard to hypotheses related to the contact with Norman French (e.g., Fischer 1992, 2004, 2006; Mustanoja 1960); and (d) regarding hypotheses related to the contact with Norse, the northern/eastern Middle English present participle ending -ande, the reduction in case agreement and the V2 syntax (see also Emonds and Faarlund 2014; Bech and Walkden 2016, for the opposite view).

Moreover, it appears that contact-induced changes are prevalent in instances of full bilingualism and code-switching (Fischer 2013). In this respect, results from studies on bilingual language acquisition could lead to a new analysis of the contact-induced change: grammatical changes are likely to happen in instances of successive acquisition of bilingualism (Meisel 2011). In general, studies have shown that imperfect learning, with interference of a first language in the learning of a second/later adopted language, also leads to shift-induced interference (Fischer 2013). All relevant examples of contact scenarios reveal crucial information on aspects of the principles that operate in the context of contact and change (e.g., imperfect L2 learning mechanisms, or economy in language change). Moreover, other significant diachronic parameters, such as the relationship between internal developments and contact-induced changes, the position of the contrast between learned and vernacular language and the differences between written and oral contact (Lavidas 2018) should constitute central questions in any analysis of the development of English.

\section{An overview of the different types of historical contact in English}

The aim of the present overview is to discuss the position of language contact in the development of English and, more specifically, the different types of influence that can be observed in contact with different languages - Celtic, Latin, Old Norse, French - and the types of patterns that have driven grammatical (and lexical) borrowing in Old and Middle English. The different types of influence are evident in the hypotheses expressed regarding contact-induced change in the history of English: for instance, the hypothesis of Celtic substratal influence is mainly related to toponymic borrowings and, with respect to grammar, verbal nouns, whereas Old Norse has been thought to affect verb-second constraints in northern Middle English varieties. Latin, on the other hand, is considered to be mainly involved in the development of the English infinitival constructions.

Moreover, the sociolinguistic aspect of the investigation of contact is related to the substratal position of the Celtic speakers, in contrast with the adstratal relationship (which includes mixing and coexistence) between the speakers of English and those of Old Norse. Only the latter relationship resulted in the borrowing of more than 200 loanwords, including everyday words (e.g., bag or knife) and pronouns such as their and them (Hundt and Schreier 2013). The sociolinguistic context of contact with Norman French is of a different type and can be described as the result of a superstratal relationship, also followed by a language shift to English (in the late Middle English period). The above context of contact with Norman French has as its main characteristic the borrowing of more than 10,000 loanwords from Norman French to English.

Fischer (2013) has shown the differences in the parameters involved in the contact of English with Latin, Scandinavian, and French. For instance, in terms of agentivity, both Latin contact (in the Old and Middle English periods) and French contact (in the Middle English period) show recipient agentivity and imitation, in contrast with Scandinavian contact, which shows source agentivity and adaptation. Latin and French contact present many similarities: for instance, in both cases, the percentage of the population speaking the contact language is small, again in contrast with Scandinavian contact; their socioeconomic status and their language prestige are high, in contrast with Scandinavian contact, in which the status and the prestige of 
the two languages is equal. The only parameter where French and Scandinavian contact contrasts with Latin contact is that of the influence on the lexicon: the influence is large in the case of Scandinavian and French contact but small in the case of Latin contact. However, the influence in Latin and French contact concerns the formal lexicon, whereas in Scandinavian contact it concerns the informal lexicon.

In the following sections, we briefly present the main characteristics of the contact of English with Latin, Celtic, French, and Old Norse; and we compare the various types of contact.

\subsection{Latin}

The peculiarities of Latin contact are related to the fact that Latin affected English during several periods (and Latin loanwords appeared in English in various stages: continental borrowing before $450 \mathrm{AD}$; during the settlement period [450-650 AD]; due to the Christianization of the Anglo-Saxons after 650 AD [among others, Kastovsky 1992; Vezzosi 2012]). Moreover, Latin influenced English mainly through the use of Latin as the language of the written medium, church, culture and administration. Latin was the dominant language in religious and literary registers, and its acquisition as a second language further developed a contact situation. Even the oral use of Latin became possible, to a degree, in mass, preaching, and among the clergy, as well as in school instruction (Timofeeva 2010). ${ }^{1}$

The main areas examined concerning the influence of Latin on English syntax are related to infinitival and participial constructions: the nominativus- and accusativus-cum-infinitivo constructions, the passive infinitive, and the absolute construction (ablativus absolutus). Most linguists agree that the nominativuscum-infinitivo and the absolute construction are mainly attested in translations from Latin and probably did not affect English native syntax (among others, Kohnen 2003; Timofeeva 2010). There is no consensus, however, on the case of the accusativus-cum-infinitivo and the passive infinitive constructions. The development of the word order in English has been considered a significant parameter for the rise of the new features of infinitives (among others, Fischer et al. 2000; Los 2005). English shifted toward a fixed SVO order, which facilitated the emergence of the Latin accusativus-cum-infinitivo construction. On the contrary, in Old English word orders, the object of a transitive infinitive appears before the infinitive (SOV order). In the Middle English orders, the object of the infinitive can appear after the infinitive. ${ }^{2}$

\subsection{Celtic}

The "Celtic hypothesis" has been an active debate for more than a century now, with a rise of interest in it in the past few decades (for instance, in the 1990s, starting with Poussa [1990], with regard to the periphrastic do). One of the first explorations of grammatical borrowing from Celtic can be found in the case of the progressive form (see, for instance, the early study of Keller [1925]). ${ }^{3}$ All discussions of possible borrowing consider the following crucial criterion: the other Germanic languages do not show parallels. This is also the case of the English progressive form, but with the exceptions of the Dutch folk-speech and the Low German dialect of Westfalish (which, however, probably use the infinitive rather than the -ing form or a verbal noun). On the contrary, early parallels of this construction in Scottish dialects (where it is strongly preserved until now) and northern English provide evidence for a Celtic influence on the progressive form of English. ${ }^{4}$

1 In such contact situations, this type of "bilingualism" involves literary rather than oral competence in most of the cases: for instance, literary competence in Latin was a widespread phenomenon in medieval England, when people used Latin in legal documents and correspondence.

2 The above observations can be used as arguments in favor of the approach that Latin influence on syntax of English was possible when the synchronic grammar of English permitted it.

3 Based on this hypothetical transfer, the English progressive form derived from the use of the verbal noun as the predicate of the verb, with emergence of a progressive form during the Middle English period (Filppula 2012).

4 For instance, according to Filppula et al. (2008), both the early and the modern Celtic influence concern the same type of structures. 
Another key phenomenon for the Celtic hypothesis is the it-cleft construction (Ball 1991, among many others). It-cleft constructions, even though they already constitute an Old English characteristic, show very low frequencies in Old English. Moreover, earlier studies have concluded that Old English it-clefts (hit-clefts) do not match the Modern English constructions with specification reading or stressed focus (on the contrary, it-cleft constructions present new information) (Ball 1991).

Other phenomena of English that have been assumed as possibly influenced by Celtic include the Northern Subject Rule, evidenced in many North Midlands and northern dialects (which have inherited this phenomenon from northern Middle English). According to the Northern Subject Rule, the nature and the position of the subject determines whether or not the inflectional verbal marker $-s$ is present. ${ }^{5}$ This type of agreement is rare in the languages of the world and is found mainly in verb-initial languages.

\subsection{French}

In the case of contact with French, most previous studies emphasized the fact that we always refer to dialects or varieties of French when we discuss the French contact: for example, we refer to Norman French, the insular Anglo-Norman (Anglo-French), or the Parisian Central French (Skaffari 2012).

Norman French (or Old Northern French), a French variety influenced by the Scandinavian dialect of the Vikings who settled in Normandy, was also the result of language contact. The period of the loss of Normandy (1204) is the latest point at which Anglo-Normans became bilinguals, even though French was used long after the early $13^{\text {th }}$ century by the upper classes. By contrast, the acquisition of French by English speakers was only driven by a need for "civil servants" who knew both French and English (Skaffari 2012).

The Parisian French is the most prestigious dialect since the $12^{\text {th }}$ century (Lodge 1993). Its influence on English was significant already from the first decades of the $13^{\text {th }}$ century, through the written medium.

The following phenomena have been mainly investigated in connection with influence from French varieties (see Mustanoja 1960): the historical Present, the $2^{\text {nd }}$-person pronouns and the relationship of pronouns and politeness (the plural ye, instead of thou, was also used as a singular pronoun). Three articles in the present special issue offer additional detailed information on the case of the French contact.

\subsection{Old Norse}

Scandinavian raiders started their expeditions in the late $8^{\text {th }}$ century, and most of eastern and northern England was under Danish control during the second half of the $9^{\text {th }}$ century. Norse was still in use in the $11^{\text {th }}$ century in northern England and perhaps in the $12^{\text {th }}$ century in the North-West (Parsons 2001, among many others). The type of contact between Norse and English could also be considered a "dialect contact," due to significant similarities between the two languages and the likelihood of mutual intelligibility (Dance 2012). In contrast, there are great differences between the various geographical areas in terms of the rate of attrition of Norse in the Scandinavian communities of England.

The borrowing of Old Norse grammatical features and words can be described as the result of a shift-based interference. The Norse speakers were responsible for the transfer of Norse elements into English because they switched their spoken language to English. As a result, the outcome of the Old Norse - English contact could be characterized as an inter-language, or a koine, or even a new variety.

The above type of contact has been considered responsible for influence on the inflectional morphology. For instance, with the northern/eastern Middle English present participle ending -ande, the reduction in case agreement and the loss of grammatical gender have been examined as possible candidates of showing influence from Norse. Other developments in Middle English morpho-syntax explained in connection with the contact with Norse include the emergence of the future auxiliaries shall and will, the shift to VO order, the

5 In these cases, the verb in the Present has the -s suffix in all persons and numbers if it is not adjacent to a personal pronoun subject. However, the $-s$ suffix also always appears if the verb is $3^{\text {rd }}$ person singular. 
characteristics of the Verb-second syntax (in northern Middle English, for instance), the increase in productivity of the derivational affixes - $n$ - and - $l$ - (as in deepen and sparkle), the rise of the "phrasal verbs," and the change of up into an aspectual marker.

\section{New directions in research on historical contact in English: the present special issue}

The articles of the special collection open new directions regarding the aforementioned questions about language contact in early English: Raymond Hickey connects the research on the contact between Celtic and English with broad questions about types and effects of contact scenarios in English and beyond, in early English and in modern dialects of English. Carola Trips opens new directions for considering the ways structures can be borrowed and explores the possibility of grammatical influence in the relation between reflexives borrowed from Old French and their use in impersonal constructions of Middle English. Emily Reed adds the parameter of pragmatic borrowing between English and Anglo Norman and introduces aspects of investigation of pragmatic contact and of exchange of conversational behaviors between languages. Christophe Béchet returns to examples of possible contact-induced change in English but with a probabilistic multifactorial model: he shows the significance of experimental procedures in the exploration of contact and combines corpus-based methodologies and the Construction Grammar framework. Lidija Štrmelj adds the factor of the written nature of contact through biblical translations and compares the translation of Graecisms and Semitisms of the Latin source text in Old and Middle English biblical translations.

The contribution of the articles is also related (in more detail) to the following aspects of language contact and change in the history of English. Hickey's article presents an overview of research conclusions on the contact between Celtic and English, offering significant insights into the types and effects of contact scenarios. He explores the contact between forms of Celtic and English, both in the first stages of the Old English period and in the early modern period in Ireland. His paper examines examples of contact-induced change in the case of Celtic and English and makes generalizations that can be applied to other instances of contact. He demonstrates that, in the case of shift situations, contact effects are complex. In this respect, it appears that the manner of language acquisition plays a significant role: language acquisition in a non-restrictive context (without formal instruction) leads to the establishment of characteristics of adult second-language acquisition of the contact variety.

Trips investigates the possibility of grammatical influence on Middle English in the case of the relationship between impersonal constructions and the reflexive use of psych verbs. In particular, she examines the relation between reflexives borrowed from Old French and their use in impersonal constructions in Middle English. Her lexicon-based and corpus-based studies of the psych verb remembren evidence that reflexive and impersonal constructions share an intransitive structure with an EXPERIENCER subject and middle semantics. Moreover, Trips discusses in detail the effects of language contact through translations: both the reflexive and the impersonal constructions are options for translators in rendering the reflexive use of the Old French verbs. Trips argues that the contact with Old French led to the increasing use of reflexive constructions that express middle semantics; on the other hand, the impersonal constructions can also be seen as translation effects to a degree.

Reed's article investigates the position of pragmatic development in scenarios of language contact. Reed identifies a similar process in the pragmaticalization of swearing, both in Middle English and Anglo-Norman. She offers new dimensions for the study of contact between English and Anglo-Norman, previously restricted to the lexicon, introducing the aspect of investigation of pragmatic contact and of exchange of conversational behaviors between languages. She demonstrates strong similarities in conversational behaviors between Middle English and late Anglo-Norman, supporting Ingham's idea of Anglo-Norman as a contact variety that is influenced by English and that influences English.

Béchet's study emphasizes the significance of frequency patterns and experimental procedures in the exploration of contact. He examines the complex prepositions of the preposition-noun-preposition (PNP) 
type and the influence of French on English, based on a probabilistic multifactorial model. His article demonstrates the ways English conforms with and deviates from the French complex preposition characteristics in the case of in lieu of and in place of. Béchet proposes an explanation of borrowing as a socio-cognitive mechanism, combining corpus-based methodologies and the Construction Grammar framework to analyze instances of language change.

Štrmelj examines the written type of contact through biblical translations. According to her conclusions, the Old English translation of the Graecisms and Semitisms of the Latin version of St. John's Gospel differs significantly from their Middle English translation: the Old English translation uses existing Germanic words, broadening their meaning and new Germanic compounds; the Middle English translation uses Latin and French loanwords. Štrmelj argues that the Latin and French loanwords are preferred in the Middle English translation because they have been integrated completely into the language, four centuries after their original borrowing. In contrast, the English words used in the Old English biblical translation underwent changes that did not allow these words further to express the Graecisms and Semitisms of the source text in the Middle English translation.

Through different perspectives, the articles attempt to answer two major questions that concern historical language contact in English. First, how are the different types of contact related to the different types of change and its explanations, based on characteristics of bilingualism and other mechanisms? Second, what are the differences and similarities between contact in early English (and early periods of languages, in general) and contact in early modern or contemporary English? The articles answer the above questions, establishing a dialogue with earlier studies and opening new perspectives. They do not propose the same way of examining the relevant material and the contact scenarios. On the contrary, they emphasize different aspects, whose combination, however, can offer the overall "picture" of the nature of the historical language contact: our conclusions on historical contact should consider the following parameters, discussed in the articles of the special issue: what we can learn from the differences between grammatical, lexical, but also pragmatic borrowing; how contact-induced change can be related to influence on words, but also to influence on structures; how we can secure our conclusions on early language contact through comparison with modern varieties, but also through probabilistic multifactorial models.

\section{References}

Ball, Catherine N. 1991. The historical development of the it-cleft. PhD Dissertation. University of Pennsylvania dissertation. https://repository.upenn.edu/dissertations/AAl9125587.

Bech, Kristin \& George Walkden. 2016. English is (still) a West Germanic language. Nordic Journal of Linguistics 39(1). 65-100. Dance, Richard. 2012. English in contact: Norse. In Alexander Bergs \& Laurel J. Brinton (eds.), English historical linguistics: An international handbook, Vol. 2, 1724-1737. Berlin \& New York: Mouton de Gruyter.

Emonds, Joseph Embley \& Jan Terje Faarlund. 2014. English: The language of the Vikings. Olomouc: Palacký University.

Filppula, Markku. 2012. Exploring grammatical differences between Irish and British English. In Bettina Migge \& Máire Ní Chiosáin (eds.), New perspectives on Irish English, 85-99. Amsterdam: John Benjamins.

Filppula, Markku, Juhani Klemola \& Heli Paulasto. 2008. English and Celtic in contact. New York: Routledge.

Fischer, Olga. 1991. The rise of the passive infinitive in English. In Dieter Kastovsky (ed.), Historical english syntax, 141-188. Berlin: Mouton de Gruyter.

Fischer, Olga. 1992. Syntax. In Norman Blake (ed.), The Cambridge history of the english language, Vol. II: 1066-1474, 207-408. Cambridge: Cambridge University Press.

Fischer, Olga. 1994. The development of quasi-auxiliaries in English and changes in word order. Neophilologus 78. $137-164$.

Fischer, Olga. 2004. Developments in the category adjective from Old to Middle English. Studies in English Medieval Language and Literature 19.1-36.

Fischer, Olga. 2006. On the position of adjectives in Middle English. English Language and Linguistics 10(2). 253-288.

Fischer, Olga. 2013. The role of contact in English syntactic change in the Old and Middle English periods. In Marianne Hundt \& Daniel Schreier (eds.), English as a contact language, 18-40. Cambridge: Cambridge University Press.

Fischer, Olga, Ans van Kemenade, Willem Koopman \& Wim van der Wurff. 2000. The syntax of Early English. Cambridge: Cambridge University Press.

Hundt, Marianne \& Daniel Schreier. 2013. Introduction: Nothing but a contact language... In Daniel Schreier \& Marianne Hundt (eds.), English as a contact language, 1-17. Cambridge: Cambridge University Press. 
Kastovsky, Dieter. 1992. Semantics and vocabulary. In Richard M. Hogg (ed.), The Cambridge history of the English language, Vol. 1, 290-408. Cambridge: Cambridge University Press.

Keller, Wolfgang. 1925. Keltisches im englischen Verbum. Anglica: Untersuchungen zur englischen Philologie, Vol. 1: Sprache und Kulturgeschichte, 55-66. Leipzig: Mayer und Müller.

Klemola, Juhani. 2013. English as a contact language in the British Isles. In Daniel Schreier \& Marianne Hundt (eds.), English as a contact language, 75-87. Cambridge: Cambridge University Press.

Kohnen, Thomas. 2003. The influence of "latinate" constructions in Early Modern English: Orality and literacy as complementary forces. In Dieter Kastovsky \& Arthur Mettinger (eds.), Language contact in the history of English, 171-194. Frankfurt am Main: Peter Lang.

Lavidas, Nikolaos. 2018. Cognate noun constructions in Early Modern English. The case of Tyndale's New Testament. In Hubert Cuyckens, Hendrik De Smet, Liesbet Heyvaert \& Charlotte Maekelberghe (eds.), Explorations in English historical syntax, 51-76. Amsterdam: John Benjamins.

Lodge, R. Anthony. 1993. French, from dialect to standard. London, New York: Routledge.

Los, Bettelou. 2005. The rise of the to-infinitive. Oxford: Oxford University Press.

Meisel, Jürgen M. 2011. Bilingual language acquisition and theories of diachronic change: Bilingualism as cause and effect of grammatical change. Bilingualism: Language and Cognition 14(2). 121-145.

Mustanoja, Tauno F. 1960. A middle English syntax. Helsinki: Société Neophilologique.

Nagucka, R. 2003. Latin prepositional phrases and their Old English equivalents. In Dieter Kastovsky \& Arthur Mettinger (eds.), Language contact in the history of English, 251-265. Frankfurt am Main: Peter Lang.

Parsons, David N. 2001. How long did the Scandinavian language survive in England? Again. In James Graham-Campbell, Richard Hall, Judith Jesch \& David N. Parsons (eds.), Vikings and the Danelaw: Select Papers from the Proceedings of the Thirteenth Viking Congress, 299-312. Oxford: Oxbow Books.

Poppe, Erich. 2003. Progress on the Progressive? A report. In Hildegard L. C. Tristram (ed.), Celtic Englishes III. Proceedings of the Third Potsdam Colloquium on Celtic Englishes, 65-84. Heidelberg: Winter.

Poussa, Patricia. 1990. A contact-universals origin for periphrastic do, with special consideration of OE-Celtic contact. In Sylvia M. Adamson, Vivien A. Law, Nigel Vincent \& Susan Wright, Papers from the 5th International Conference on English Historical Linguistics, 407-434. Amsterdam: Benjamins.

Skaffari, Janne. 2012. English in contact: French. In Alexander Bergs \& Laurel J. Brinton (eds.), English historical linguistics: An international handbook, Vol. 2, 1671-1686. Berlin \& New York: Mouton de Gruyter.

Timofeeva, Olga. 2010. Anglo-Latin bilingualism before 1066: Prospects and limitations. In Alaric Hall, Olga Timofeeva, Ágnes Kiricsi \& Bethany Fox (eds.), Interfaces between language and culture in Medieval England: A Festschrift for Matti Kilpiö, 1-36. Leiden: Brill.

Trudgill, Peter. 2016. Contact-related processes of change in the early history of English. In Merja Kytö \& Päivi Pahta (eds.), The Cambridge Handbook of English historical linguistics, 318-334. Cambridge: Cambridge University Press.

Vezzosi, Letizia. 2012. English in contact: Latin. In Alexander Bergs \& Laurel J. Brinton (eds.), English historical linguistics: An international handbook, Vol. 2, 1703-1719. Berlin \& New York: Mouton de Gruyter. 